\title{
ADOÇÃO DE CRIANÇAS E ADOLESCENTES COM DEFICIÊNCIA: REVISÃO DE LITERATURA
}

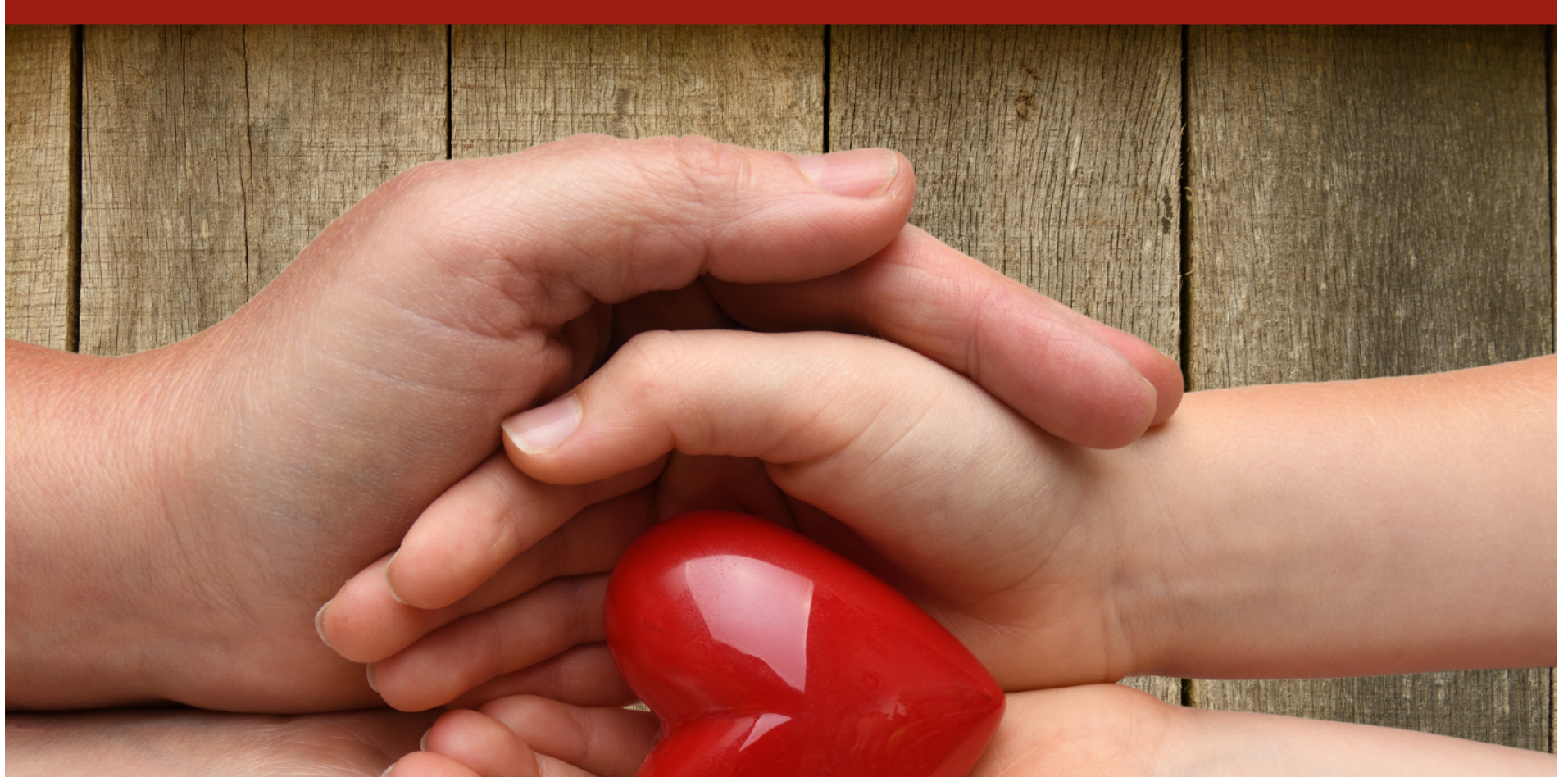


NATHALIA IZABEL FERREIRA DE VASCONCELOS

PETRONIO WALQUIRIO DE BARROS JUNIOR

PAULA ORCHIUCCI MIURA

ADOÇÃO DE CRIANÇAS E ADOLESCENTES COM DEFICIÊNCIA: REVISÃO DE LITERATURA

$1^{\text {a }}$ ed.

Piracanjuba-GO

Editora Conhecimento Livre

Piracanjuba-GO 
$1^{\mathrm{a}} \mathrm{ed}$

Dados Internacionais de Catalogação na Publicação (CIP)

VASCONCELOS, NATHALIA IZABEL FERREIRA DE

V117A ADOÇÃO DE CRIANÇAS E ADOLESCENTES COM DEFICIÊNCIA: REVISÃO DE

LITENATURAIA IZABEL FERREIRA DE VASCONCELOS. PETRONIO WALQUIRIO DE

BARROS JUNIOR. PAULA ORCHIUCCI MIURA. - Piracanjuba-GO

Editora Conhecimento Livre, 2021

22 f.: il

DOI: $10.37423 / 2021 . e d c 1246$

ISBN: 978-65-89145-88-2

Modo de acesso: World Wide Web

Incluir Bibliografia

1. adoção 2. crianças-e-adolescentes-com-deficiência 3. revisão-de-literatura I. VASCONCELOS, NATHALIA IZABEL FERREIRA DE II. JUNIOR, PETRONIO WALQUIRIO DE BARROS III. MIURA, PAULA ORCHIUCCI IV. Título

CDU: 150

https://doi.org/10.37423/2021.edc1246

O conteúdo dos artigos e sua correção ortográfica são de responsabilidade exclusiva dos seus respectivos autores. 


\section{EDITORA CONHECIMENTO LIVRE}

\section{Corpo Editorial}

Dr. João Luís Ribeiro Ulhôa

Dra. Eyde Cristianne Saraiva-Bonatto

MSc. Anderson Reis de Sousa

$\underline{\text { MSc. Frederico Celestino Barbosa }}$

MSc. Carlos Eduardo de Oliveira Gontijo

MSc. Plínio Ferreira Pires

Editora Conhecimento Livre

Piracanjuba-GO 
ADOÇÃO DE CRIANÇAS E ADOLESCENTES COM DEFICIÊNCIA: REVISÃO DE LITERATURA
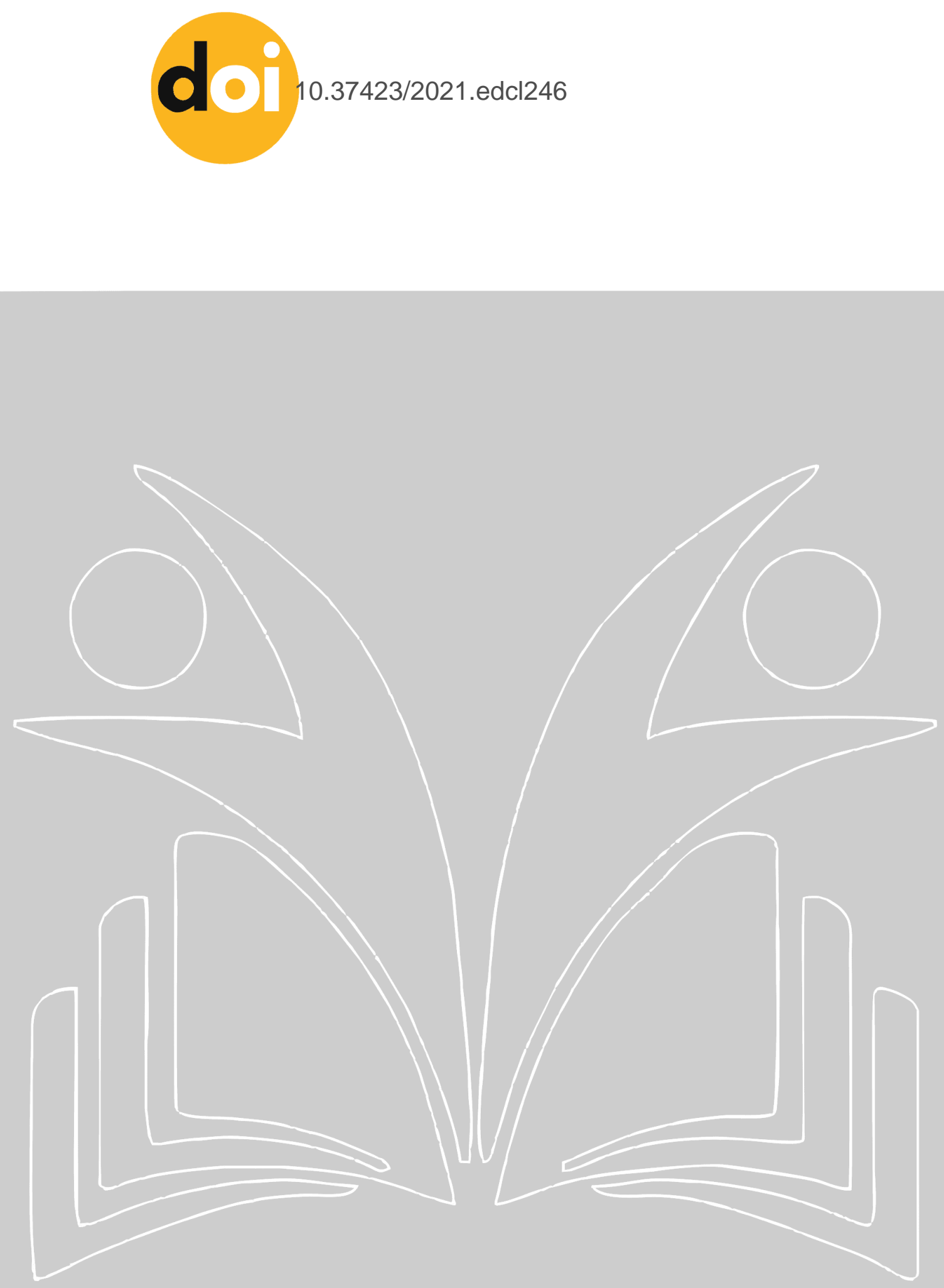
Resumo: A adoção de criança e adolescente com deficiência é identificada por meio do Sistema Nacional de Adoção e na literatura acadêmica como uma das mais difíceis de acontecer no cenário nacional. O presente trabalho teve como objetivo identificar e analisar as produções acadêmicas brasileiras sobre adoção de crianças e adolescentes com deficiência. O método utilizado foi a revisão sistemática do tipo metassíntese, que permitiu definir critérios de inclusão e exclusão de material, resultando em oito artigos para a amostra final. Foram identificadas três categorias temáticas: Profissionais envolvidos no processo de adoção; Crenças, motivações e obstáculos acerca da adoção de pessoas com deficiência; Parentalidade na adoção de pessoas com deficiência. Conclui-se que vários fatores influenciam na dificuldade em adotar crianças e adolescentes com deficiência, desde a crença de não ser capaz de cuidar até o preconceito social. Para os que adotam pessoas com deficiência, destacou-se o altruísmo como impulsionador nesse tipo de adoção, além disso, identificou-se a necessidade de haver preparação, conhecimento, paciência e maturidade dos pais adotivos. A equipe multidisciplinar formada por assistentes sociais e psicólogos está inserida em todas as etapas do processo de adoção e se faz necessária para auxiliar a adoção. E por fim o envolvimento familiar na rotina do adotado(a) contribui para o desenvolvimento do filho(a) em sua nova família.

Palavras-chave: Adoção, Crianças e Adolescentes com Deficiência, Revisão de Literatura. 


\section{INTRODUÇÃO}

O significado da palavra adoção - etimologicamente deriva da palavra adoptione, que significa considerar, olhar para, escolher - pode ser compreendido como a inserção de uma criança ou adolescente em um ambiente familiar, cujos pais não podem ou não querem assumir o desempenho das suas funções parentais. Ocorre de forma definitiva e com aquisição de vínculo jurídico próprio da filiação, segundo as normas legais em vigor (DINIZ, 1994, p.13).

A adoção é uma prática antiga já retratada em escritos bíblicos. A história de Moisés é um desses casos que envolvem adoção, conforme descrito por Paiva (2004), aproximadamente no ano 1250 a. C., por determinação do faraó, todas as crianças israelitas do sexo masculino deveriam ser mortas ao nascer. A mãe de uma dessas crianças colocou seu filho dentro de um cesto e jogou no rio, pois talvez assim, ele sobrevivesse. O menino foi encontrado e adotado pela filha do faraó, recebeu o nome de Moisés e se tornou o herói do povo hebreu.

No Brasil, a história da adoção é delineada desde o período da colonização. Adotar um filho ou filha era um ato relacionado à caridade. Comumente havia nas casas das pessoas mais abastadas os "filhos de criação", que eram pessoas que moravam nas casas e faziam atividades domésticas. Apesar de não ser uma situação legalmente formalizada, esse tipo de adoção acontecia e servia como oportunidade para essas famílias ter pessoas trabalhando em suas casas de forma gratuita (PAIVA, 2004), ao mesmo tempo em que prestavam assistência aos mais necessitados. Isto é, foi com a possibilidade de ter trabalhadores e exercer caridade cristã pregada pela igreja, que a prática da adoção se construiu no país. De modo geral, o interesse genuíno não era cuidar da criança necessitada ou abandonada, visto que essas pessoas eram tratadas de modo inferior (MAUX; DUTRA, 2010).

Silva Filho (1997) aponta 1828 como o ano em que tratou-se da adoção na legislação brasileira pela primeira vez através do Código Civil, porém, o intuito era priorizar as famílias sem filhos biológicos, solucionando, portanto, essa questão. Com o passar do tempo, essa prática foi se modificando e sendo entendido que a adoção não se trata de dar um/a filho/a para um casal, mas de dar mães e pais a um/uma filho/a (NATALIO, 2001). Segundo Gomes (2006), de acordo com a teoria winnicottianna o fator mais relevante quando se decide adotar deve estar na capacidade da família de cuidar de uma criança ou adolescente, adaptando-se às necessidades destes sujeitos ao longo de seu amadurecimento e não em seus desejos inconscientes. 
Com a Constituição da República Federativa do Brasil de 1988, os filhos passaram a ser tratados de modo igualitário, conforme preceitua o art. 227, §6ㅇ, “Os filhos, havidos ou não da relação do casamento, ou por adoção, terão os mesmos direitos e qualificações, proibidas quaisquer designações discriminatórias relativas à filiação" (BRASIL, 1988).

Mudanças nas leis foram acontecendo até culminar no Estatuto da Criança e do Adolescente (ECA), Lei 8.069, de 13 de julho de 1990, que, de acordo com seu art. 1ㅇ, "Dispõe sobre a proteção integral à criança e ao adolescente" e assim, regulamentou a prática de adoção no Brasil há 30 anos (BRASIL, 1990).

Outras modificações ocorreram com a Lei 12.010/09, também chamada de Nova lei da Adoção, que objetiva priorizar o direito da criança e adolescente de viver em uma família, seja a biológica ou a substituta, a fim de evitar seu esquecimento na instituição, e garantindo que as suas necessidades sejam favorecidas, dentre as quais a convivência familiar (BRASIL, 2009).

O art. 50, § 3o, da Lei 12.010 de 3 de agosto de 2009, explicita que:

A inscrição de postulantes à adoção será precedida de um período de preparação psicossocial e jurídica, orientado pela equipe técnica da Justiça da Infância e da Juventude, preferencialmente com apoio dos técnicos responsáveis pela execução da política municipal de garantia do direito à convivência familiar (BRASIL, 2009).

Para Dias (2006), embora à avaliação psicossocial no processo de habilitação seja feita com os pretendentes, a aceitação pelos demais familiares pode ser fundamental para o sucesso da adoção, pois a criança ou adolescente só é de fato adotado quando passa a fazer parte da tradição de suas famílias materna e paterna.

De acordo com Winnicott (1955/1997 apud OTUKA et al., 2012), é essencial que o novo ambiente familiar seja estável, contínuo e promova o desenvolvimento saudável do adotando a fim de que a adoção seja uma experiência positiva e o novo lar suficientemente bom para o/a novo/a integrante dessa família.

Ainda sobre a Lei 12.010 de 3 de agosto de 2009, o vínculo sanguíneo também é considerado importante no que diz respeito a situações de irmãos que estão aguardando serem adotados. A justiça dá preferência para que sejam adotados juntos pela nova família, conforme consta no texto do art. 28, § 40: 
Os grupos de irmãos serão colocados sob adoção, tutela ou guarda da mesma família substituta, ressalvada a comprovada existência de risco de abuso ou outra situação que justifique plenamente a excepcionalidade de solução diversa, procurando-se, em qualquer caso, evitar o rompimento definitivo dos vínculos fraternais (BRASIL, 2009).

Porém, trata-se de adoções consideradas mais difíceis de acontecer, visto que, a literatura mostra a preferência dos pais em adotar crianças que, normalmente, não existem no Brasil para serem adotadas. Após preenchimento do Cadastro de Adoção, os requerentes à adoção podem indicar as características do pretenso adotável, tais como: sexo, cor de pele, idade, aspectos de saúde e se aceitam irmãos (ARAUJO; FARO, 2017).

Para Araújo e Faro (2017), de acordo com pesquisa realizada pelo Conselho Nacional de Justiça em 2013, há mais crianças com idade acima dos cinco anos para adoção do que as de até 2 anos, como é mais, comumente, desejado. A faixa etária que há disponível por si só já caracteriza um grupo menos propenso a ser adotado e a situação se agrava se apresentarem além da idade mais avançada, características pouco desejáveis: serem negras, formarem grupo de irmãos, apresentarem deficiências ou problemas de saúde.

Segundo Fonseca, Santos e Dias (2009), existe um alto número de candidatos e candidatas na fila de espera para a adoção e inúmeras crianças e adolescentes adotáveis nas instituições de acolhimento, mas que não o são, por se tratarem de adoções mais difíceis de acontecer, as denominadas 'adoções necessárias', que são: adoções inter-raciais, de irmãos, de crianças maiores e de crianças com necessidades especiais.

Visto que a literatura, normalmente, mostra pesquisas realizadas separadamente de cada grupo que compõem as chamadas 'adoções necessárias' devido à complexidade de cada uma delas, optou-se por enfocar em um grupo específico: adoção de pessoas com deficiência. Esse recorte justifica-se pelo duplo preconceito e discriminação sofridos por quem vive privações por estar em instituições de acolhimento, assim como segregação na sociedade por ter deficiências (CAMPOS; ARAÚJO, 2018).

O conceito de deficiência, segundo a Lei 13.146 em seu art. 2 o, diz que pessoa com deficiência é "aquela que tem impedimento de longo prazo de natureza física, mental, intelectual ou sensorial, o qual, em interação com uma ou mais barreiras, pode obstruir sua participação plena e efetiva na sociedade em igualdade de condições com as demais pessoas" (BRASIL, 2015).

Segundo o Sistema Nacional de Adoção e Acolhimento (SNA), no site do Conselho Nacional de Justiça (CNJ), no mês de novembro de 2020, existiam 5.166 crianças e adolescentes juridicamente aptos à 
adoção e 35.878 pretendentes habilitados judicialmente a adotá-los. Dessas 5.166, cerca de 11,3\% (585) possuem algum tipo de deficiência, seja física, intelectual ou ambas, e 7,4\% das pessoas aptas para adotar aceitam crianças com algum tipo de deficiência, ou seja, 2.645 pessoas. De acordo com este levantamento, há mais pessoas para adotar que crianças e adolescentes disponíveis.

Ainda segundo o SNA, embora o número de pretendentes aptos para adotar seja quatro vezes maior que o número de pessoas disponíveis para serem adotadas, apenas 1,1\% dos adotados (49) nos anos de 2019 e 2020, possuíam algum tipo de deficiência. A adoção de crianças e adolescentes com deficiências físicas, intelectuais ou ambas fazem parte de um percentual muito pequeno comparado aos demais tipos de adoções.

Em 5 de fevereiro de 2014, entra em vigor a Lei 12.955 que faz alterações no Estatuto da Criança e Adolescente e prioriza processos de adoção quando o adotando ou a adotanda for criança ou adolescente com deficiência ou com doença crônica (BRASIL, 2014).

Mesmo com leis em vigor que priorizam a adoção de crianças e adolescentes com deficiência, ainda se percebe a carência de material na literatura, fazendo com que as discussões permeiem em pequenos grupos, como por exemplo, o de pessoas que buscam adoção. Dessa forma, ressalta-se a relevância acadêmica e social desse trabalho que tem por finalidade potencializar reflexões e discussões acerca dessa temática e contribuir com a promoção de direitos dessas pessoas, as quais, muitas vezes e equivocadamente, são vistas como vidas inferiores/limitadas, sofrendo inclusive, violências e violações de direitos.

Portanto, este artigo tem como objetivo identificar e analisar as produções acadêmicas sobre adoção de crianças e adolescentes com deficiência, registrando os métodos utilizados nessas produções, bem como, revistas e instituições que mais publicaram artigos científicos sobre essa temática, para discutir, de acordo com o material encontrado, a importância da Psicologia em realizar pesquisas sobre a adoção de pessoas com deficiência.

\section{MÉTODO}

Trata-se de uma revisão sistemática de literatura, uma modalidade de pesquisa que segue protocolos próprios a fim de buscar compreender, dando lógica a um grande corpus documental. Para atingir seu propósito, faz-se necessário descrever as bases de dados bibliográficos em que foram consultados e as estratégias de busca empregadas em cada uma delas, os critérios de seleção, inclusão e exclusão dos artigos científicos, bem como processo de análise de cada artigo (GALVÃO; RICARTE, 2019). 
A revisão sistemática utilizada foi do tipo metassíntese, método que analisa em detalhes resultados alcançados em abordagens qualitativas. De acordo com Oliveira et al. (2015), se caracteriza como "uma estratégia metodológica, que proporciona a interpretação dos resultados encontrados em pesquisas realizadas, numa área determinada do conhecimento, ou diferentes áreas que mantenham um objetivo de interesse comum" (p. 148), conduzindo além de uma análise crítica, a produção de um novo conhecimento.

Foi realizado um levantamento bibliográfico nas bases de dados Scientific Electronic Library Online (Scielo), Periódicos Eletrônicos de Psicologia (PePSIC) e Coordenação de Aperfeiçoamento de Pessoal de Nível Superior (CAPES), utilizando-se os seguintes descritores com operador booleano AND, a fim de obter resultados combinando os termos da pesquisa: "adoção AND deficiência", "adoção AND deficiente", "adoção AND necessidades especiais"; "adotado AND deficiência", "adotado AND deficiente", "adotado AND necessidades especiais" e "adotivo AND deficiência", "adotivo AND deficiente", "adotivo AND necessidades especiais", com a finalidade de identificar as produções científicas com a temática que abarca adoção de pessoas com deficiência.

Os critérios de inclusão para seleção foram: somente artigos científicos publicados em periódicos científicos, por se tratarem de estudos que passam por processo de avaliação, ampliando, assim, as possibilidades de um rigoroso controle de qualidade a respeito da qualidade desse material; publicados em português; publicados entre os anos de 2010 a 2020 a fim de abarcar o período de 10 anos, para garantir dados mais atualizados sobre o tema.

Os critérios de exclusão foram: textos que não fossem artigos científicos, tais como, dissertações, monografias, teses, resenhas, livros, editoriais etc.; publicações anteriores ao ano de 2010, publicações que se distanciavam do tema proposto desse trabalho.

Após leitura dos títulos e resumos dos artigos resultantes da pesquisa, os artigos foram lidos na íntegra e, assim, excluídos materiais duplicados e que não tinham como cerne a discussão sobre adoção de crianças e adolescentes com deficiência.

Para análise dos dados coletados, foi utilizado o método proposto por Bardin (2011), a análise de conteúdo, conjunto de técnicas que segue de forma sistemática as seguintes etapas: pré-análise, exploração do material e tratamento dos resultados, inferência e interpretação. Visto que o método possibilita a formação de categorias temáticas, foram elaboradas três categorias para discussão e análise das produções que discorrem sobre o tema adoção de pessoa com deficiência. 


\section{RESULTADOS E DISCUSSÃO}

Foram encontrados o total de 1.830 artigos de acordo com pesquisa realizada no mês de dezembro de 2020. Após leitura dos resumos dos materiais, foram descartados os textos que se distanciaram do objetivo geral proposto, ou seja, que não tinha em sua base de discussão o tema "adoção de crianças e adolescentes com deficiência", sendo selecionados, portanto, 8 artigos, para serem lidos na íntegra, de acordo com a Tabela 1.

Tabela 1: Quantidade de artigos encontrados nas etapas iniciais da metassíntese e por base de dados

ADOÇÃO DE CRIANÇAS E ADOLESCENTES COM NECESSIDADES ESPECIAIS

\begin{tabular}{|c|c|c|c|c|c|}
\hline \multicolumn{3}{|c|}{ EXPLORAÇÃO } & REFINAMENTO & CRUZAMENTO & TOTAL \\
\hline \multicolumn{3}{|c|}{$\begin{array}{l}\text { Critérios de Inclusão: } \\
\text { - Últimos } 10 \text { anos } \\
\text { - Estudos primários } \\
\text { - Língua portuguesa }\end{array}$} & $\begin{array}{l}\text { Selecionadas as } \\
\text { produções: } \\
\text { 1- Com temas afins } \\
\text { 2- Disponíveis para }\end{array}$ & $\begin{array}{l}\text { Repetições interbase } \\
\text { e/ou interdescritor }\end{array}$ & $\begin{array}{l}\text { Produç̧ões } \\
\text { selecionado para } \\
\text { leitura na integra }\end{array}$ \\
\hline Descritores & Portais & $\begin{array}{c}\mathrm{N}^{\circ} \text { de } \\
\text { produções } \\
\text { encontradas }\end{array}$ & $\begin{array}{l}\mathrm{N}^{\circ} \text { de produções } \\
\text { selecionadas }\end{array}$ & $\begin{array}{l}\mathrm{N}^{\circ} \text { de produções } \\
\text { repetidas }\end{array}$ & $\begin{array}{c}\mathrm{N}^{\circ} \text { de produções } \\
\text { para análise }\end{array}$ \\
\hline \multirow{3}{*}{$\begin{array}{l}\text { "adoção and } \\
\text { deficiência", } \\
\text { "adoção and } \\
\text { deficiente", } \\
\text { "adoção and } \\
\text { necessidades } \\
\text { especiais", } \\
\text { "adotado and } \\
\text { deficiência", } \\
\text { "adotado and } \\
\text { deficiente", } \\
\text { "adotado and } \\
\text { necessidades } \\
\text { especiais", } \\
\text { "adotivo and } \\
\text { deficiência", } \\
\text { "adotivo and } \\
\text { deficiente", } \\
\text { "adotivo and } \\
\text { necessidades } \\
\text { especiais" }\end{array}$} & SciELO & 81 & 1 & --- & 1 \\
\hline & PEPSIC & 8 & 4 & --- & 4 \\
\hline & CAPES & 1741 & 6 & 3 & 3 \\
\hline Total & 3 & 1830 & 11 & 3 & 8 \\
\hline
\end{tabular}

Fonte: autores, 2021. 
A tabela 1 mostra a quantidade de artigos encontrados nas etapas iniciais da metassíntese com os descritores utilizados (adoção AND deficiência, adoção AND deficiente, adoção AND necessidades especiais; adotado AND deficiência, adotado AND deficiente, adotado AND necessidades especiais e adotivo AND deficiência, adotivo AND deficiente, adotivo AND necessidades especiais) em cada base de dados (SciELO, PEPSIC e CAPES). Após aplicação dos filtros (produções brasileiras, artigos científicos, publicados nos últimos 10 anos e em língua portuguesa), totalizaram-se para análise dos dados 1 artigo na SciELO, 4 no PEPSIC e 3 na CAPES, finalizando com 8 artigos.

\section{DESCRIÇÃO}

Com o objetivo de descrever as produções acadêmicas selecionadas para análise, a leitura possibilitou extrair alguns dados sobre os artigos publicados. Com relação as revistas, pode-se observar: Psicologia: Teoria e Pesquisa, com três publicações; Psico- USF, com duas; Revista da SPAGESP, Revista Educação Especial, Estilos da Clínica, Cadernos da Psicanálise e Pensando Famílias tiveram 1 publicação cada (ver Tabela 2).

Tabela 2: Quantidade de produções publicadas de acordo com a revista.

\begin{tabular}{ll}
\hline Revistas que publicaram & Quantidade de publicações \\
\hline Psico- USF & 2 \\
\hline Psicologia: Teoria e Pesquisa & 1 \\
\hline Revista da SPAGESP & 1 \\
\hline Revista Educação Especial & 1 \\
\hline Estilos da Clínica & 1 \\
\hline Cadernos da Psicanálise & 1 \\
\hline Pensando Famílias & 1 \\
\hline
\end{tabular}

Fonte: autores, 2021.

Sobre a quantidade de autores por publicação, notou-se que dos 8 artigos analisados, 5 foram escritos por 2 autores(as), enquanto 3 estudos tiveram a autoria de 3 pessoas por trabalho publicado. Do total de 13 autores(as), somente 2 são homens, prevalecendo maior quantidade de pesquisas sobre o tema por pessoas do sexo feminino, demonstrando, portanto, maior interesse das mulheres a respeito do assunto. Foi observado também que em 6 artigos os autores(as) se repetem, constatando uma pequena diversidade de pesquisadores sobre essa temática. 
Em termos da instituição de origem dos (as) autores(as), todos(as) são originários(as) de universidades com destaque para a Universidade do Vale do Itajaí (3), Universidade Federal do Pará (2), Universidade Federal de Santa Maria (2), Universidade Federal de Uberlândia (2), Universidade Federal do Triângulo Mineiro (2), Universidade Federal do Rio Grande do Sul (1) e Universidade de São Paulo (1). Desse modo, demonstra-se a carência de mais pesquisas sobre adoção de crianças e adolescentes com deficiência por parte das regiões nordeste e centro-oeste do país.

Conforme Figura 1, em relação a quantidade de artigos publicados por ano, a pesquisa demonstrou que entre anos de 2010 a 2014 não foram encontradas publicações e que entre os anos de 2015 a 2020 foi publicado um artigo por ano com exceção dos anos de 2017 e 2018, que veicularam dois artigos por ano, totalizando 8 artigos publicados na última década.

Figura 1 Quantidade de artigos publicados por ano, de 2010 a 2020.

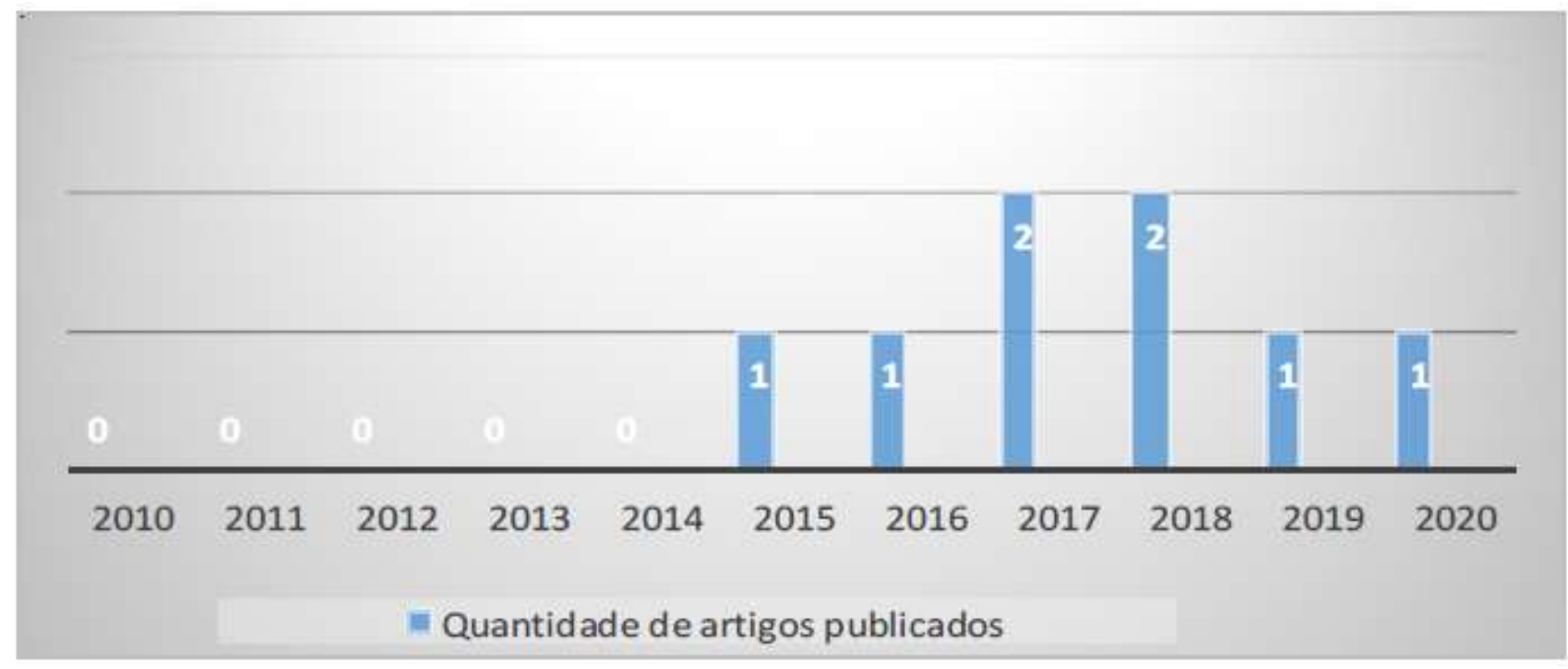

Fonte: autores, 2021.

Sobre os métodos utilizados nas produções, nota-se a prevalência do estudo de caso. Para Pereira et al. (2009), estudo de caso é um estudo aprofundado de um objeto de modo detalhado, amplo e flexível que pode obter dados através de observações, entrevistas e arquivos, preservando a totalidade do objeto. Estudos de caso foram utilizados em três produções, revisão integrativa de literatura em duas, estudo documental em uma, entrevista semiestruturada em uma e revisão bibliográfica em outra. 
Tabela 4: Quantidade de artigos de acordo com o método.

\begin{tabular}{lc}
\hline Método & Quantidade de artigos \\
\hline Estudo de caso & 3 \\
\hline Revisão integrativa de literatura & 2 \\
\hline Estudo documental & 1 \\
\hline Entrevista semiestruturada & 1 \\
\hline Revisão bibliográfica & 1 \\
\hline
\end{tabular}

Fonte: autores, 2021.

\section{ANÁLISE}

Com base na análise dos artigos foram identificadas três categorias temáticas: Profissionais envolvidos no processo de adoção; Crenças, motivações e obstáculos acerca da adoção de pessoas com deficiência; Parentalidade na adoção de pessoas com deficiências.

\section{PROFISSIONAIS ENVOLVIDOS NO PROCESSO DE ADOÇÃO}

Compreender o universo da adoção é entender, primeiramente, como funciona (ou as diferentes formas que podem funcionar) seu processo. O envolvimento de profissionais de diferentes áreas no processo de adoção é tratado em dois dos oito artigos analisados. Cecílio e Scorsolini-Comin (2018) retratam a importância dos profissionais que compõem a equipe responsável por dar suporte a decisão judicial e apoio aos pais e mães que pretendem adotar crianças e adolescente com ou sem deficiência. Teixeira e Rampelotto (2017) defendem que os profissionais da educação especial poderiam auxiliar a equipe do judiciário nos casos de adoção de pessoas com deficiência.

Sobre os ambientes aos quais a criança e o(a) adolescente estão inseridos(as) à espera da adoção, é possível mencionar a instituição de acolhimento e a escola (quando a criança já está em fase escolar). Nesse universo, encontram-se os profissionais que trabalham nas instituições de acolhimento e nas escolas, e também, a equipe técnica responsável pelo processo de adoção. Teixeira e Rampelotto (2017) e Cecílio e Scorsolini-Comin (2018) retratam a importância das pessoas implicadas no processo de adoção e que fazem parte das vivências do(a) adotando(a) e/ou da criança ou adolescente adotado(a).

Cecílio e Scorsolini (2018) destacam o estudo psicossocial como ferramenta fundamental para auxiliar no parecer final sobre a adoção. A escuta e o esclarecimento proporcionado pela equipe 
multidisciplinar composta por assistentes sociais e psicólogos(as) se mostram essenciais para auxiliar nas adoções, fazendo com que haja uma maior probabilidade dessas adoções serem bem-sucedidas. O estudo psicossocial ou avaliação psicossocial ocorre durante todo o processo de adoção, desde os contatos iniciais com a(s) pessoas(s) que almejam adotarem à adaptação do(a) adotando(a) a nova família, despertando aspectos emocionais nos pais e mães diante do desconhecido, do que está por vir, além de contribuir dando subsídios para as decisões judiciais.

Cecílio e Scorsolini (2018) discutem a importância do(a) profissional de psicologia perante o desafio de encontrar uma família para criança ou adolescente, buscando compreender as fantasias e o lugar que o(a) adotando(a) ocupará no imaginário da nova família, bem como minimizar a ansiedade, medo, dúvidas, angústias, expectativas e frustrações enfrentadas na espera desse(a) filho(a). Pontuam ainda, a discrepância entre a quantidade de pessoas que querem adotar em relação as que estão disponíveis para adoção, relatando que os perfis das crianças e adolescentes à espera de serem adotados(as), compõem as chamadas adoções necessárias, sendo, portanto, mais difíceis de se concretizarem. Destacam-se nesse grupo as crianças e adolescentes com deficiências.

Outro profissional que pode auxiliar os pais e mães que adotam ou pretendem adotar criança ou adolescente com deficiência são os responsáveis pela educação especial. Teixeira e Rampelotto (2017) demonstram em seu estudo que, devido a sua experiência em trabalhar com pessoas com deficiências no ambiente escolar, os profissionais da educação especial poderiam compor as equipes que orientam candidatos(as) a adotar criança ou adolescente com deficiência, juntamente com os psicólogos(as) e assistentes sociais, uma vez que, a escola é um dos componentes da rede de apoio da família e exige que os(as) profissionais estejam atentos(as) aos aspectos familiares que refletem no desempenho escolar de seus alunos. Mesmo a adoção de criança e adolescente com deficiência não sendo, na maioria dos casos, a preferência na escolha de quem adota, por diversas razões, as autoras afirmam que o ambiente escolar é um local de troca de conhecimento e auxílio mútuo entre os pais e mães e os(as) professores(as) e que através de atenção e estímulo por parte da família e da escola, ambos podem auxiliar no desenvolvimento dessas crianças e adolescentes.

O artigo de Rosseti-Ferreira et al. (2012) corrobora a importância dos profissionais envolvidos no processo, ressaltando a necessidade de um programa de acompanhamento da família antes e depois da adoção que inclua encontros com a família, professores e pessoas que participam da vida da criança e adolescente. 


\section{CRENÇAS, MOTIVAÇÕES E OBSTÁCULOS ACERCA DA ADOÇÃO DE PESSOAS COM DEFICIÊNCIA}

Os três artigos (SILVA CAVALCANTE; DELL'AGLIO, 2016, SILVA; VITORINO;

PORTES, 2018, BORGES; SCORSOLINI-COMIN, 2020) que compõem essa categoria traçam um perfil das pessoas que aceitam adotar crianças ou adolescentes com deficiência e detectaram que, no geral, são pessoas com escolaridade incompleta e renda baixa. Enfatizaram a escassez de estudos acerca dessa temática. E concordam quanto à importância da preparação dos futuros pais e mães antes de adotarem, do acompanhamento psicológico durante o processo de adoção, inclusive pós adoção.

Borges e Scorsolini-Comin (2020) trazem o conceito de adoções necessárias - já mencionado anteriormente - e reiteram que esse tipo de adoção é mais difícil de acontecer devido ao estigma de pessoas "inadotáveis", incluindo a pessoa com deficiência a esse grupo. Perceberam maior flexibilização e disponibilidade em adoções internacionais, mesmo sendo a última alternativa, e também, por casais do mesmo sexo. Afirmam a importância da rede de apoio para enfrentamento de dificuldades e fortalecimento de vínculos, podendo destacar a escola e o acompanhamento psicológico como importantes aliados. Perceberam que a maioria dos postulantes a adoção não aceita crianças e adolescentes com doenças crônicas ou deficiências, mas os que aceitam, são mais abertos a deficiências físicas em detrimento dos transtornos mentais.

Silva, Cavalcante e Dell'Aglio (2016) fazem um estudo documental sobre os pretendentes a adoção no Brasil e perceberam que pouco se estuda sobre a temática no país, sendo provenientes, normalmente de outros países. Em suas investigações, concluíram que pessoas dispostas a adotar crianças com deficiência não demonstram exigências quanto a cor da pele e ao sexo, são famílias de baixo nível socioeconômico, mas que tem uma rede de apoio que lhes auxilia, especialmente quando os níveis de estresse estão elevados.

Silva, Vitorino e Portes (2018) investigam as crenças das pessoas que pretendem adotar em relação a adoção de pessoa com deficiência. Os autores fazem referência a pesquisas que afirmam que muitos pretendentes acreditam não ter capacidade de cuidar de um filho(a) com deficiência. Silva, Vitorino e Portes (2018) constataram que a maior motivação das pessoas em optar pela adoção ainda está relacionado com infertilidade ou incapacidade de ter filhos biológicos. Mesmo que a adoção seja em prol, principalmente, de dar uma família a criança e/ou adolescente, ainda é possível verificar que a adoção seja motivada por dar filhos a pessoas que não podem ter por laços sanguíneos. Sobre a idealização de ter um filho, constataram que os futuros pais pensam em filhos sem problemas, 
parecidos biologicamente com eles. E o artigo mostrou que, para os pais e mães pretendentes a adoção, para adotar uma criança ou adolescente com deficiência tem que ter o dom e estes, preferem aguardar mais tempo na fila de espera à adotar um(a) filho(a) com deficiência.

O artigo de Fonseca, Santos e Dias (2009) apontam uma diversidade de motivações na escolha da adoção de crianças com necessidades especiais, dentre elas, projeto de adotar há tempo, infertilidade, escolher o sexo do filho, conhecimento dos maus tratos sofridos por essas crianças. Enquanto as dificuldades, relataram burocracia no processo de adoção, dificuldade em conseguir cuidadores, preconceito da sociedade, situação econômica difícil e não aceitação por um dos cônjuges.

Nota-se que as pessoas sente-se inseguras, acreditando que não serão capazes de cuidar de um(a) filho(a) com deficiência, por diversos motivos: seja pela dependência que acreditam que a criança ou adolescente terá, seja por falta de apoio ou recursos financeiros. De modo geral, o altruísmo é apontado como impulsionador nesse tipo de adoção, mas, além disso, é necessário que haja preparação, conhecimento, paciência, maturidade para lidar com essas crianças ou adolescentes e suas necessidades.

\section{PARENTALIDADE NA ADOÇÃO DE PESSOAS COM DEFICIÊNCIAS}

A parentalidade na adoção de crianças e adolescentes com deficiência é temática encontrada em três dos oito artigos analisados. Bossa e Neves $(2017,2018)$ são autoras que se mostram interessadas no tema adoção de pessoa com deficiência, buscando compreender a partir da psicanálise, o que sustenta a relação entre a díade mãe e filho(a) com deficiência adotado(a).

Bossa e Neves $(2017,2018)$ discutem em seus estudos a adoção de criança com deficiência a partir do olhar psicanalítico trazendo o conceito de unheimlich apresentado por Freud em sua obra "O estranho". Unheimlich nas traduções em diversas línguas pode ser entendido como: "estrangeiro, hora ou lugar estranho, inquietante, desconfortável, sombrio, obscuro, assombrado, repulsivo, sinistro, suspeito, lúgubre, demoníaco" (MARTINI; COELHO JUNIOR, 2010, p. 373). A ambivalência do termo designa algo que causa horror e medo na mesma medida que contem seu oposto, algo conhecido, familiar ou heimlich. Apresentam a deficiência como algo próprio do humano, mas que sofreu ao longo dos tempos, inúmeras tentativas de exclusão, causando estranhamento a essa condição.

Bossa e Neves (2017) vão para além dos conceitos descritos acima, trazendo o pathos, termo grego que remete a paixão, no sentido de passividade, assujeitamento, sofrimento, como se através dele fosse possível converter tal sofrimento em vivência para constituição de subjetividade. Esse artigo 
aponta que a adoção da pessoa com deficiência, assim como qualquer outra forma de maternidade, busca preencher a falta. Desse modo, sugerem estudos sobre as histórias das mães que optam em adotar pessoa com deficiência e as manifestações subjetivas que lhes movem.

Em relação a deficiência, Bossa e Neves (2018) indicam dificuldades na formação de vínculos dos pais com a criança. O preconceito é apontado como elemento que interfere na escolha das adoções necessárias. Para as autoras, diferente da imagem construída pelos pais e mães do filho imaginado, a deficiência fere a imagem que está ligada a perfeição narcísica. Para uma aceitação da deficiência, é preciso elaborar o estranhamento que a imagem real desse filho(a) Ihes proporciona, e assim, idealizar a criança a partir da realidade.

Silva e Cavalcante (2015) fazem uma investigação sobre rotinas familiares de crianças com necessidades especiais que foram adotadas, definindo as rotinas familiares como "regularidades comportamentais presentes no dia a dia das pessoas e grupos em diferentes contextos familiares"(p.173). O artigo apresenta que o lazer é potencializador para socialização na primeira infância e na vida adulta, a frequência na escola é importante, pois ela desempenha papel fundamental para o desenvolvimento das crianças, atividades que dizem respeito a alimentação e higiene auxiliam na maturação biológica. Concluem que, a rede social de apoio da família, a quem as autoras referemse como contextos ecológicos, é fundamental para melhorar a cognição, socialização, aquisições emocionais e processos de maturação biológica e todos que fazem parte da rotina dessas crianças com deficiência desenvolvem-se mutuamente e adquirem habilidades e conhecimento para lidar melhor com elas.

Embora a deficiência seja uma questão que tenda a causar estranhamento e que por diversas razões adotar uma pessoa com necessidades especiais não seja prioridade, pais e mães que se envolvem e participam da vida do(a) filho(a) com deficiência, percebem que cada pessoa, independente de ter deficiência ou não, tem ritmos de aprendizagem e desenvolvimento diferentes uns dos outros. As autoras Fonseca, Santos e Dias (2009) apontam para a importância da rede de apoio social aos pais e mães que adotam pessoa com deficiência e destacam que quem opta por esse tipo de adoção, relativiza a concepção do que é ser normal, passando a enxergar cada pessoa de modo singular.

\section{CONSIDERAÇÕES FINAIS}

Esta pesquisa buscou identificar e analisar as produções acadêmicas sobre adoção de crianças e adolescentes com deficiência. Constatou-se que, dos artigos analisados, os métodos utilizados nas 
produções foram diversos, prevalecendo estudos de casos. Quanto à revista que mais publicou sobre o tema foi a Psico-USF, enquanto as instituições de vinculação dos(as) autores(as) foram variadas. Observou-se que a maioria das pesquisas é de autoria de pessoas do sexo feminino e não foram localizadas publicações de pesquisadores vinculados às instituições das regiões nordeste e centrooeste do Brasil.

Os estudos relacionados à adoção de criança e adolescente com deficiência retrataram o importante suporte da equipe técnica para a decisão judicial sobre a adoção, destacando o papel do profissional de psicologia que além de auxiliar o(a) juiz(a) no parecer final sobre a adoção, é responsável em acompanhar os futuros pais durante todo o processo, elucidando dúvidas acerca da adoção, inclusive esclarecendo sobre adoção de pessoas com necessidades especiais. Outras pesquisas trouxeram as crenças sobre adotar alguém com deficiência, os fatores que motivaram os pais e mães, tendo destaque o altruísmo e os obstáculos enfrentados pela família adotante. E para finalizar, estudos trouxeram a importância da participação parental na rotina desses(as) filhos(as) para seu desenvolvimento.

Ressalta-se a necessidade da psicologia se fazer presente em todas as etapas do processo de adoção, principalmente no que tange pessoas com deficiências. A falta de conhecimento sobre o assunto, faz com que muitas pessoas que têm o desejo em adotar, não aceite um(a) filho(a) com deficiência pela falta de esclarecimento e apoio psicológico. A escuta e o acompanhamento psicológico, não só dos(as) filhos(as), mas dos(as) cuidadores(as) se mostram fundamentais para auxiliar na constituição da família nessa jornada.

Embora haja uma lei que dentre várias alterações acerca da adoção, possibilitou acelerar e priorizar a adoção dos que têm deficiências, percebe-se que ainda há pouca discussão sobre o assunto, bem como publicações que esclareçam e gerem reflexões sobre o tema, especialmente na área de psicologia.

Em suma, a revisão possibilitou compreender o universo que permeia a adoção de crianças e adolescentes que têm deficiências, as peculiaridades desses tipos de adoções através das produções científicas publicadas nos últimos dez anos. Sugere-se mais pesquisas relacionadas ao tema, uma vez percebida a dificuldade em encontrar material publicado acerca do assunto e ressalta-se a importância de mais discussões sobre adoções de pessoas com deficiências, pois são adoções necessárias e possíveis. 


\section{REFERÊNCIAS}

AMIRALIAN, M. L. T. M. Deficiêcias: Um novo olhar. Contribuições a partir da psicanálise winnicottiana. Estilos clin., São Paulo, v. 8, n. 15, p. 94-111, jun. 2003.

ARAUJO, A. I. S. F.; FARO, A. Motivações, dificuldades e expectativas acerca da adoção: perspectivas de futuros pais adotivos. Psicol. rev. (Belo Horizonte), Belo Horizonte, v. 23, n. 3, p. 790-810, dez. 2017

BARDIN, L. Análise de conteúdo. São Paulo: Edições, 2011.

BORGES, C. A. P.; SCORSOLINI-COMIN, F. As Adoções Necessárias no Contexto Brasileiro: Características, Desafios e Visibilidade. Psico-USF, Campinas, v. 25, n. 2, p. 307- 320, Jun. 2020.

BOSSA, D. F.; NEVES, A. S. Estranho, familiar e pathos: apreensões psicanalíticas sobre a adoção da criança com deficiência. Estilos clin., São Paulo, v. 22, n. 3, p. 455-467, dez. 2017.

BOSSA, D. F.; NEVES, A. S. O Unheimlich na adoção da criança com deficiência. Cad. psicanal., Rio de Jeneiro, v. 40, n. 38, p. 97-109, jun. 2018.

BRASIL. Constituição (1988). Constituição da República Federativa do Brasil. Brasília, DF, Senado, 1988.

BRASIL. Lei Federal №. 8069, de 13 de julho de 1990. ECA - Estatuto da Criança e do Adolescente. Brasília, DF, 1990. Disponível

em: http://www.planalto.gov.br/ccivil/LEIS/L8069.htm. Acesso em: 20 nov. 2020.

BRASIL. Lei Federal № 12.010/09, de 03 de agosto de 2009. Nova Lei Nacional da Adoção. Brasília, DF, 2009. Disponível em: http://www.planalto.gov.br/ccivil_03/_Ato2007- 2010/2009/Lei/L12010.htm. Acesso em: 20 nov. 2020.

BRASIL. Lei Federal № 12.955/14, de 03 de agosto de 2009. Facilita a Adoção de criança/adolescente com Deficiência. Brasília, DF, 2014. Disponível em: http://www.planalto.gov.br/ccivil_03/_Ato20112014/2014/Lei/L12955.htm. Acesso em 20 nov. 2020.

BRASIL. Lei Federal № 13.146/15, de 06 de julho de 2015. Lei Brasileira de Inclusão da Pessoa com deficiência. Brasília, DF, 2015. Disponível em: http://www.planalto.gov.br/ccivil_03/_ato20152018/2015/lei/l13146.htm. Acesso em: 20 nov. 2020.

CAMPOS, R. C. P. R.; ARAUJO, N. R. Situação educacional de crianças e jovens com deficiência em acolhimento institucional. Cad. Pesqui., São Paulo , v. 48, n. 170, p. 1148- 1166, 2018.

CECILIO, M. S.; SCORSOLINI-COMIN, F. Avaliação de Candidatos Pretendentes no Processo de Habilitação para Adoção: Revisão da Literatura. Psico-USF, Campinas, v. 23, n. 3, p. 497-511, Jul. 2018.

Conselho Nacional de Justiça, CNJ: Cadastro Nacional de Adoção. Disponível em: https://www.cnj.jus.br/programas-e-acoes/adocao/. Acesso em: 20 nov. 2020.

DIAS, C. M. S. B. A importância da família extensa na adoção. In SCHETTINI, L.; SCHETTINI, S. S. M. (Orgs.). Adoção: os vários lados dessa história. Recife: Bagaço, 2006. p. 173-194.

DINIZ, J. S. A adoção: Notas para uma visão global. In FREIRE, F. (Org.). Abandono e adoção: Contribuições para uma cultura da adoção II. Curitiba: Terra dos Homens, 1994. p. 13-30. 
FONSECA, C. M. S. M. S.; SANTOS, C. P.; DIAS, C. M. de S. B. A adoção de crianças com necessidades especiais na perspectiva dos pais adotivos. Paidéia (Ribeirão Preto), Ribeirão Preto, v. 19, n. 44, p. 303311, Dec. 2009.

Galvão M. C. B.; Ricartel. L. M. Revisão sistemática da literatura: conceituação, produção e publicação. Logeion: Filosofia da Informação, v. 6, n. 1, p. 57-73, 15 set. 2019.

GOMES, K. A adoção à luz da teoria winnicottiana. Winnicott e-prints, São Paulo, v. 1, n. 2, p. 1-18, 2006.

MARTINI, A.; COELHO JUNIOR, N. E. Novas notas sobre "O estranho". Tempo psicanal., Rio de Janeiro, v. 42, n. 2, p. 371-402, jun. 2010.

MAUX, A. A. B.; DUTRA, E. A adoção no Brasil: algumas reflexões. Estud. pesqui. psicol., Rio de Janeiro , v. 10, n. 2, ago. 2010.

Natalio, H. Um sentido para a vida. In FREIRE, F. (Org.). Abandono e adoção: Contribuições para uma cultura da adoção III. Curitiba: Terra dos Homens, 2001. p. 37-39.

OLIVEIRA, A. A. S. et al. Metassíntese. Apontamentos para sistematização de revisões amplas e crítica interna à produção científica. Investigação Qualitativa em Saúde, V. 1, p. 147-152, 2015.

OTUKA, L. K.; SCORSOLINI-COMIN, F.; SANTOS, M. A. Adoção suficientemente boa: experiência de um casal com filhos biológicos. Psic.: Teor. e Pesq., Brasília , v. 28, n. 1, p. 55-63, Mar. 2012.

PAIVA, L. D. Adoção: significado e possibilidades. São Paulo: Casa do Psicólogo, 2004. PEREIRA, L. T. K.; GODOY, D. M. A.; TERCARIOL, D. Estudo de caso como

procedimento de pesquisa científica: reflexão a partir da clínica fonoaudiológica. Psicol. Reflex. Crit., Porto Alegre, v. 22, n. 3, p. 422-429, 2009.

ROSSETTI-FERREIRA, M. C. et al. Acolhimento de crianças e adolescentes em situações de abandono, violência e rupturas. Psicol. Reflex. Crit., Porto Alegre, v. 25, n. 2, p. 390-399, 2012.

SILVA, F. H. O. B.; CAVALCANTE, L. I. C.; DELL'AGLIO, D. D. Pretendentes à adoção

de crianças no Brasil: um estudo documental. Rev. SPAGESP, Ribeirão Preto, v. 17, n. 2, p. 67-80, 2016.

SILVA, F. H. O. B.; CAVALCANTE, L. I. C. Rotinas Familiares de Crianças com Necessidades Especiais em Família Adotiva. Psic.: Teor. e Pesq., Brasília, v. 31, n. 2, p. 173-180, 2015.

SILVA, F. M.; VITORINO, M.; PORTES, J. R. M. Crenças dos pretendentes a adoção sobre adotar um filho com deficiência. Pensando fam., Porto Alegre, v. 23, n. 2, p. 240-255, 2019.

SILVA FILHO, A. M. O Regime Jurídico da Adoção Estatutária. São Paulo: Revista dos Tribunais, 1997.

TEIXEIRA, C. T.; RAMPELOTTO, E. M. Adoção de crianças público-alvo da Educação Especial: adaptação familiar e o contexto escolar. Revista Educação Especial, Santa Maria, v. 30, n. 57, p. 163-174, 2017.

WEBER, L. N. D. Pais e filhos por adoção no Brasil: características, expectativas e sentimentos. Curitiba: Juruá, 2001. 